\title{
A New Species of Troglocollops (Insecta: Coleoptera: Malachiidae) from Southern Primorye, Russian Far East
}

\author{
Sergei E. Tshernyshev \\ Siberian Zoological Museum, Institute of Animal Systematics and Ecology, Siberian Branch of \\ the Russian Academy of Sciences, Frunze Street, 11, Novosibirsk 630091, Russia \\ E-mail:sch-sch@mail.ru
}

(Received 8 April 2005; Accepted 26 October 2006)

\begin{abstract}
A new species of soft-winged flower beetle, Troglocollops sundukovi sp. nov., is described from southern Primorye, Russian Far East. The male head and genitalia are illustrated and compared with closely allied congeneric species. A map showing the distribution of the new species and two closely allied congeneric species occurring in Northeast Asia is presented.
\end{abstract}

Key Words: Insecta, Coleoptera, Malachiidae, Troglocollops, new species, Primorye.

\section{Introduction}

The genus Troglocollops was proposed by Wittmer (1965) for those species previously referred to the malachiid beetle genus Collops Erichson, 1840 that are distributed in the Palaearctic Region and possess a tarsal comb on the fore-legs of males. The main characters of the male, differentiating this genus from others, are as follows: head with a protuberance or depression in the middle, basal segments of antennae enlarged, and fore-tarsi each with a comb arising from the second segment. Detailed morphological characteristics of the genus were provided by Tshernyshev (1995), who also described a new subgenus on the basis of the contrasting yellow and black coloration of the body and the shape of the basal segments of the antennae. Thus, all dark-colored species with slightly swollen first and third antennal segments are attributed to the nominotypical subgenus, while the remaining species with yellow fringes of the pronotum and elytra and strongly modified basal segments of the antennae, are separated into two other subgenera, Troglocollopsoides Wittmer, 1979 (with the third antennal segment larger than the first) and Alexeus Tshernyshev, 1994 (with the third segment not larger than the first).

Among the beetles from the Lasovskiy State Reserve kindly given to the author by Dr Yurii Sundukov, I found black-blue specimens of a species assignable to Troglocollops s. str. with a head sculpture in males quite different from that of the known species. The description of this species, which is new to science, is given below. 


\section{Materials and Methods}

For the description and diagnosis of the species, some specific male characters of the head, genitalia, and urites are used. In the case of the male genitalia, the number and shape of the inner spines are diagnostic. Once studied, the genitalia were glued with G-1300 (Yo Yo) onto label paper and pinned under the specimen.

For comparative purposes, drawings of two congeneric species are presented, as well as the holotype of the new species: Troglocollops obscuricornis (Motschulsky, 1860), 1 male (Fig. 1), Yamsk village, Magadan Oblast, Russia (SZMN). Troglocollops niger Wittmer, 1992, 1 male (Fig. 2), holotype, Bajan-Ölgij, Altaj District, Mongolia (ZIN).

Specimens examined in this study are deposited in the following two museums: Siberian Zoological Museum, Institute of Animal Systematics and Ecology, Siberian Branch of the Russian Academy of Sciences, Novosibirsk, Russia (SZMN); Zoological Institute, Saint-Petersburg, Russia (ZIN).

\section{Taxonomy}

Troglocollops sundukovi sp. nov.

(Figs 3-8, 9)

Type series. Holotype: male, source of Ussuri River, Snezhnaya Mountain, southern Sikhote-Alin' range, Primorye, Russia, 1200-1400 m, taiga, 2-7 July 2004, Yu. Sundukov and V. Shohrin leg. (SZMN). Allotype: female, Lasovskiy Raion (Region), Mt. Kamen'-Brat (massif of Mt. Sestra), southern Primorye, 1500-1540 m, alpine, 3 July 2004, Yu. Sundukov and V. Shohrin leg. (SZMN). Paratypes: 2 males, 2 females, same data as allotype (SZMN); 1 male, 1 female, Sokol'chi, Karpad', Lasovskiy State Reserve, southern Sikhote-Alin' range, Primorye, 23-24 June 1980, S. Murzin leg. (ZIN); 2 females, Adjalami River, $30 \mathrm{~km}$ SW of Sovetskaya Gavan', Sikhote-Alin' range, Primorye, 15 July and 10 August 1965, O. N. Kabakov leg. (ZIN); 1 male, Khabarovsk Krai, Ekaterina Bay, Sea of Okhotsk, 2 August 1957, O. N. Kabakov leg. (ZIN).

Description. Male. Mouthparts, antennal segments 1-4, tibiae, tarsi, and vesicles yellow; trochanters and thoracic mesepimera black-brown; other body parts black-brown with blue metallic lustre. Surface of body evenly covered with fine, adpressed, brownish hairs; temple and elytra additionally with sparse, erect, brown setae.

Head slightly narrower than pronotum, shiny and lacking punctures and hairs in impression, elsewhere matte, densely punctured, and covered with thin, adpressed, brownish pubescence. Front with interocular impression (Fig. 3) wide and deep, transverse, and with arched basal margin disposed higher than upper margins of eyes; projection small, trapeziform, slightly elevated near middle of distal side of impression located approximately at level of lower margin of eyes. Genae short and straight. Clypeus narrow, transverse, straight. Labrum short, suboval, transverse. Palpi elongate; first segment transverse and 0.4 times as long as apical segment; second segment subcylindrical, 1.6 times longer than first; apical segment slender, cylindrical and acuminate distally. 


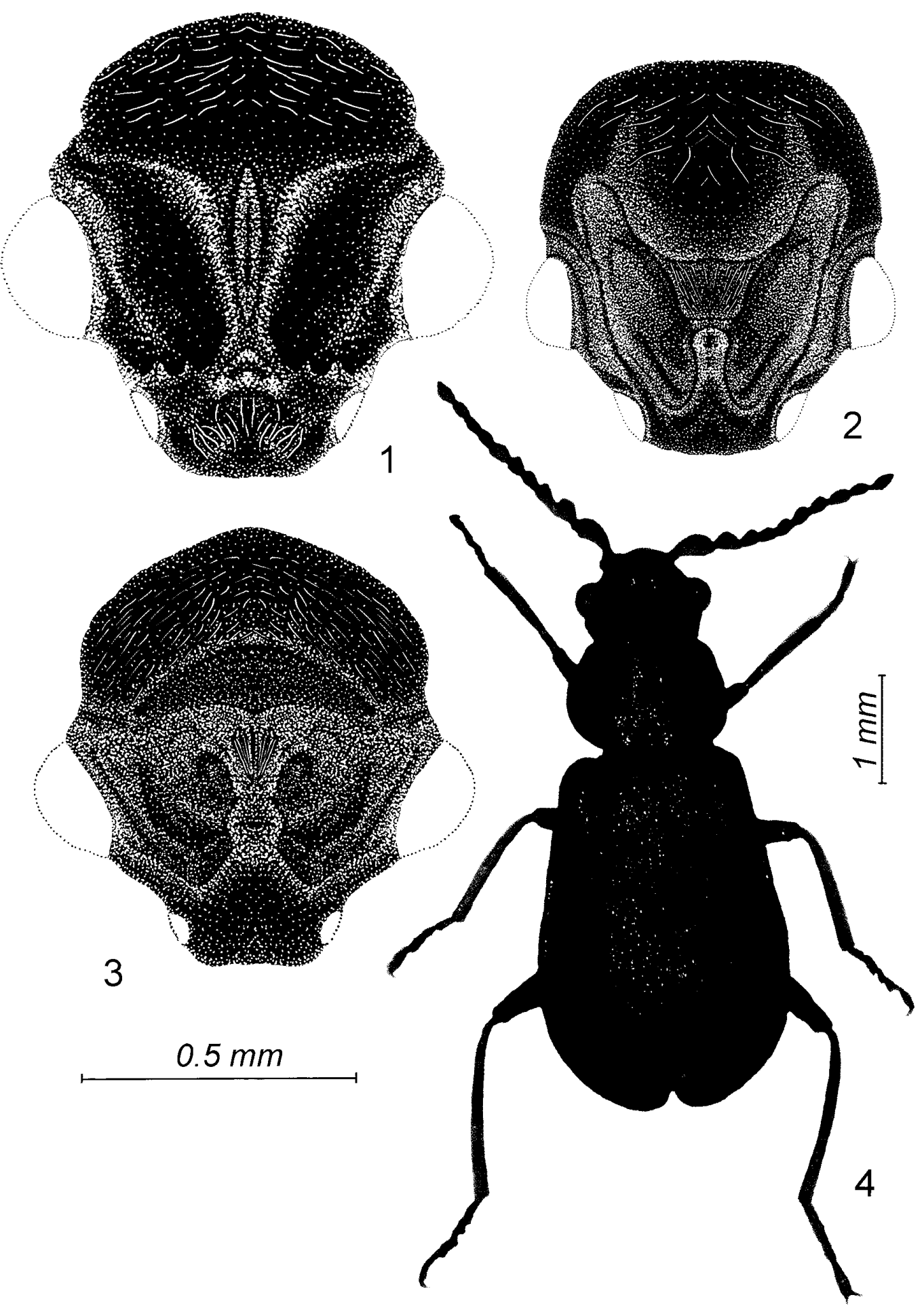

Figs 1-4. Male head (1-3) in frontal view and habitus (4) of Troglocollops spp. 1, Troglocollops obscuricornis (Motschulsky, 1860); 2, Troglocollops niger Wittmer, 1992, holotype; 3, 4, Troglocollops sundukovi sp. nov., holotype. 
Antennae (Fig. 4) reaching posterior margin of pronotum, evenly covered with short, brownish, semi-erect pubescence; segments 1 and 3 larger than all remaining segments; first segment oblongo-clavate; second segment very small, round, almost completely hidden by first; third segment triangular, two-thirds as long as first; segments 4-11 subcylindrical; apical segment evenly sinuate at apex.

Pronotum transverse, 1.4 times wider than long, densely punctured, sparsely and finely pubescent, with smooth microsculpture between punctures; anterior margin slightly convex; posterior margin straight; all angles rounded and posterior ones obliquely truncate; sides distinctly marginate; posterior part impressed near angles.

Scutellum short and transverse, almost hidden by pronotum.

Elytra oblong, widening just behind midlength, at base not wider than pronotum, shining, with punctures sparse but distinct, microsculpture smooth, and with double pubescence, sparse, semierect, brown bristles, and very fine, brownish, adpressed hairs; shoulders distinct but not protruding; apices evenly rounded, simple.

Legs of moderate size. Posterior femora not reaching elytral apices. Tibiae thin, almost straight, those cross section rounded. All tarsi five-segmented, narrow; second segments of anterior tarsi with comb extending over the segment; in all legs, claw segment longest, somewhat longer than first and second segments together in anterior and middle legs, and of same length as these in posterior legs;

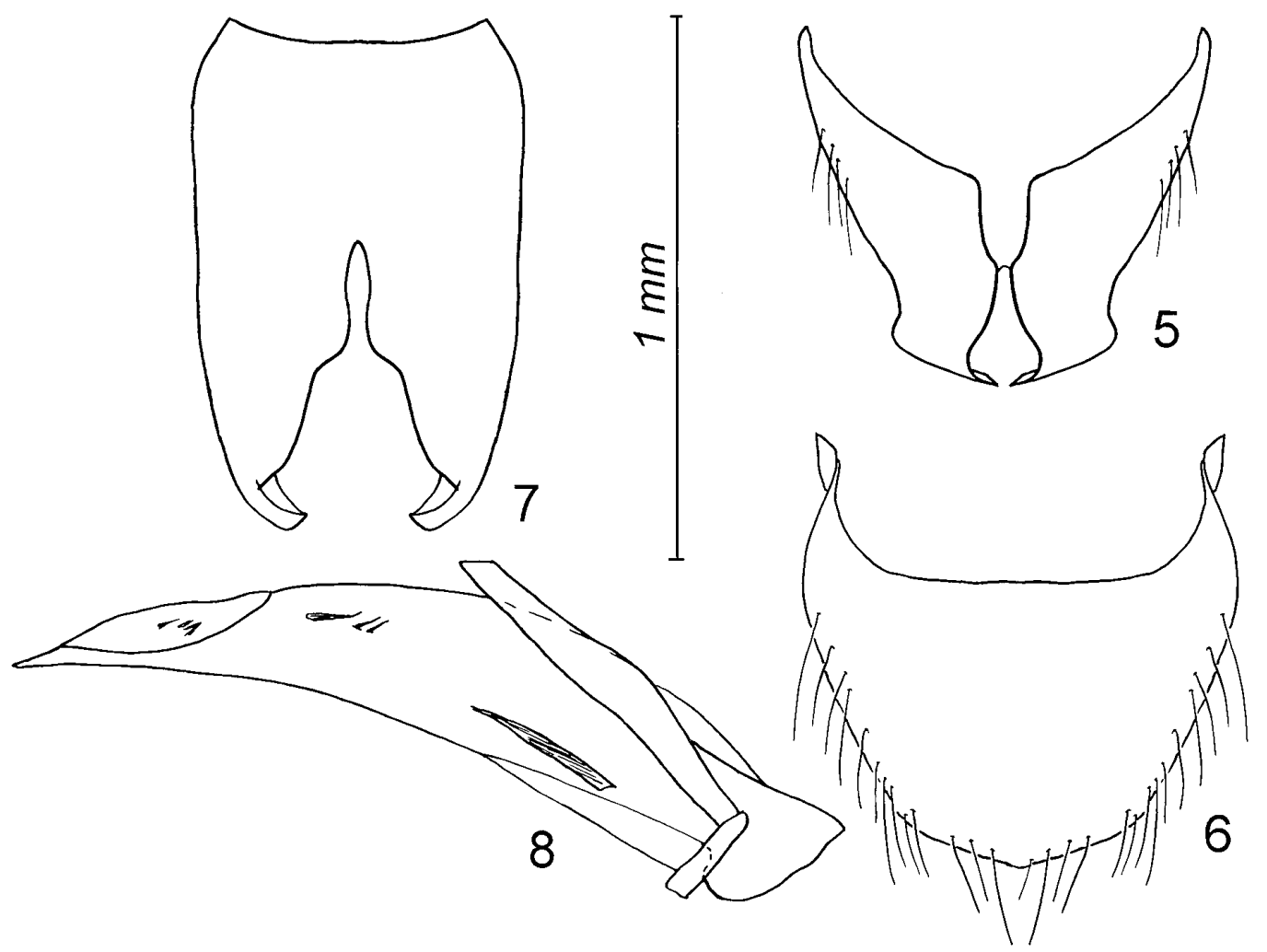

Figs 5-8. Troglocollops sundukovi sp. nov., urites and genitalia of male, holotype. 5, apical sternite; 6 , apical tergite; 7 , tegmen; 8 , aedeagus in lateral view. 
claws narrow, with small lamella at base.

Ventral surface of abdomen densely punctured, with sparse, brownish, adpressed pubescence; posterior margin of apical sternite strongly bent inwardly (Fig. 5); apical tergite transverse, 1.5 times wider than long, evenly rounded at apex (Fig. 6); tegmen elongate, with wide apodemes (Fig. 7). Aedeagus pointed; endophallus with strong spine at base and two groups of small spines near apex (Fig. 8).

Length of body $4.1 \mathrm{~mm}$, width at widest part of elytra $1.9 \mathrm{~mm}$.

Female. Similar to male except for head lacking depression and only with very small protuberance, elytra more strongly widened posteriorly, antennae narrow, and fore-tarsi without comb.

Length of body $4.7 \mathrm{~mm}$, width at widest part of elytra $2.3 \mathrm{~mm}$.

Etymology. The new species is dedicated to my colleague, Dr Yurii Sundukov, who collected specimens of this new species.

Distribution. Southern Primorye, the Far East of Russia (Fig. 9).

Habitat. The beetles, usually actively moving among mosses and lichens over rocks, were collected from alpine and taiga landscapes.

Remarks. Amongst the congeners, the new species is most similar to Troglocollops obscuricornis and T. niger, but can be easily separated from them by the following characters of the male (cf. Motschulsky 1860; Wittmer 1979): head with a deep, rounded depression on the dorsal surface, but without a conspicuous horn (Figs 3, 4); corners of forehead protruding (Fig. 3); and different shape of apical sternite and aedeagus [cf. Figs 5-8 of the present paper and Figs 6-9 and 14-17 in Tshernyshev (1995)]. In T. obscuriconis and T. niger, the head is provided with a conspicuous horn and a small impression inferior to the horn, and the corners of the forehead of these species are not produced (Figs 1, 2). Furthermore, both the

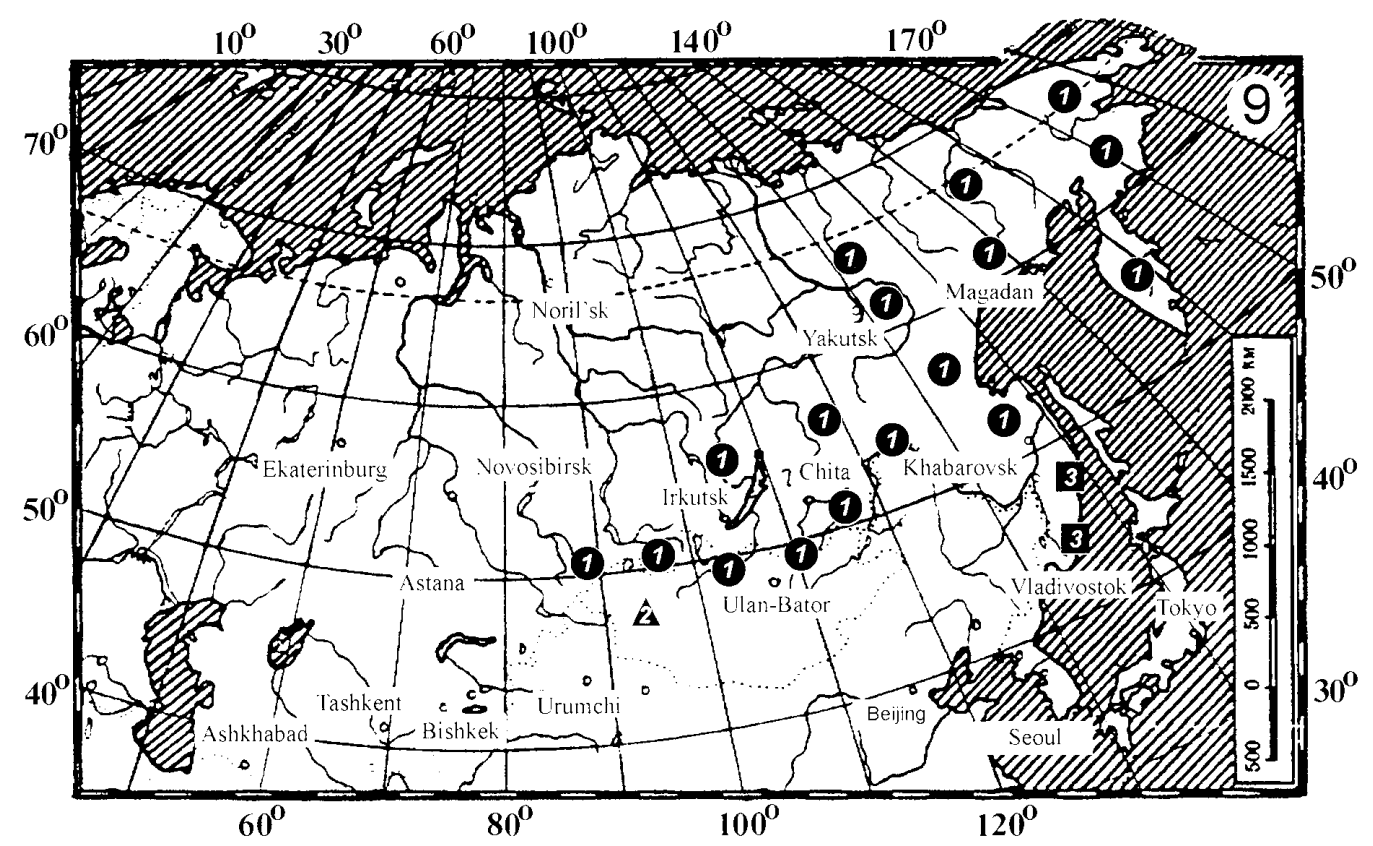

Fig. 9. Map showing the distribution of Troglocollops obscuricornis (1), T. niger (2), and $T$. sundukovi sp. nov. (3). 
male and female of $T$. sundukovi possess a distinctive blue tinge on their bodies and light-brown to yellow coloration of the fore- and intermediate tibiae, mouthparts, and the four basalmost segments of the antennae. In the other two species, such coloration is not seen.

The geographical distribution of the new species and the two closely allied species is summarized in Fig. 9.

\section{Acknowledgments}

All the newly collected material was provided from the Lasovskiy State Reserve by my colleague Dr Yurii Sundukov, to whom I express my sincere appreciation. Thanks are also due to Prof. G. S. Medvedev and Dr B. A. Korotyaev (ZIN, St.Petersburg) for the loan of material under their care, to Mrs A. K. Chistyakova (St.Petersburg) for her very kind help during my examination of the important collection of ZIN, and to Prof. M. R. D. Seaward (University of Bradford) for his kind help with the final correction of the manuscript.

\section{References}

Motschulsky, V. I. 1860. Coléoptères rapportés de la Sibérie orientale et notamment des pays situées sur les bords du fleuve Amour par MM. Schrenck, Maak, Ditmar, Voznessenski etc. déterminés et décrits par V. de Motschulsky. Pp. 77-257, tables VI-XI, 1 carte. In: Dr. L. v. Schrenck's Reisen und Forschungen im Amur-Lande. Band 2. Coleopteren. A. F. Devrien, Saint Petersburg.

Tshernyshev, S. E. 1995. A revision of the genus Troglocollops Wittmer, 1965 (Coleoptera, Melyridae, Malachiinae). Russian Entomological Journal 3-4: 51-80.

Wittmer, W. 1965. Kommt die Gattung Collops Er. (Col. Malachiidae) in der Palaearktis vor? Mitteilungen der Schweizerischen Entomologischen Gesellschaft 382: 142-144.

Wittmer, W. 1979. 65. Beitrag zur Kenntnis der palaearktischen Cantharidae und Malachiidae (Col.). Entomologischen Arbeiten aus dem Museum Georg Frey 28: 133-156. 